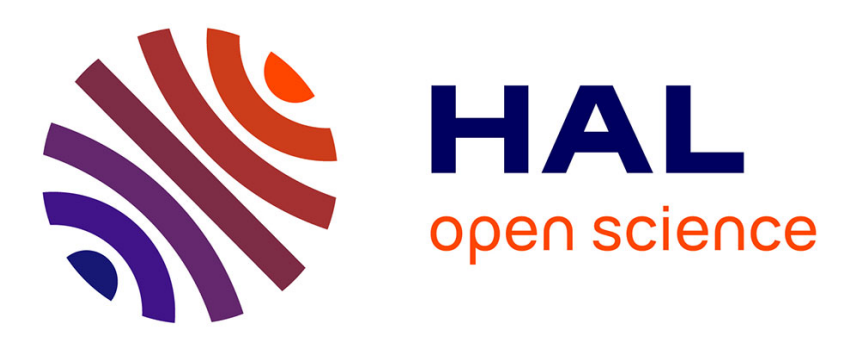

\title{
Measurements and quantitative model for edge influence on bulk resistance for circular semiconductor samples
}

\author{
J.J. Marchand, G. Chen, P. Pinard
}

\section{To cite this version:}

J.J. Marchand, G. Chen, P. Pinard. Measurements and quantitative model for edge influence on bulk resistance for circular semiconductor samples. Revue de Physique Appliquée, 1987, 22 (1), pp.71-75. 10.1051/rphysap:0198700220107100 . jpa-00245517

\section{HAL Id: jpa-00245517 https://hal.science/jpa-00245517}

Submitted on 1 Jan 1987

HAL is a multi-disciplinary open access archive for the deposit and dissemination of scientific research documents, whether they are published or not. The documents may come from teaching and research institutions in France or abroad, or from public or private research centers.
L'archive ouverte pluridisciplinaire HAL, est destinée au dépôt et à la diffusion de documents scientifiques de niveau recherche, publiés ou non, émanant des établissements d'enseignement et de recherche français ou étrangers, des laboratoires publics ou privés. 


\title{
Measurements and quantitative model for edge influence on bulk resistance for circular semiconductor samples $(* *)$
}

\author{
J. J. Marchand, G. Chen (*) and P. Pinard \\ Laboratoire de Physique de la Matière (associé au C.N.R.S.), Institut National des Sciences Appliquées de Lyon, \\ 20, avenue Albert Einstein, 69621 Villeurbanne Cedex, France
}

(Reçu le 28 juillet 1986, révisé le 16 septembre, accepté le 22 septembre 1986)

\begin{abstract}
Résumé. - Lorsqu'on étudie un composant ou un échantillon comportant deux contacts électriques, il intervient toujours une résistance due au volume. En fait, celle-ci dépend de la géométrie et des effets de bords car les échantillons sont de dimension finie. Les études effectuées par le passé sont basées sur des hypothèses théoriques, des approximations mathématiques et n'ont pas vraiment été vérifiées expérimentalement : ces formulations ne sont pas réellement utilisables quantitativement. A partir de mesures de potentiels sur des échantillons circulaires, nous présentons un modèle donnant une formulation quantitative des effets de bords, le long de l'axe reliant les deux contacts, qui est en bon accord avec les résultats expérimentaux. Nous calculons ensuite l'influence des effets de bords sur la résistance attribuée au volume.

Abstract. - The study of any two terminal device or sample always involves the presence of a bulk resistance. In fact, this resistance depends on the geometry and on edge effects due to the finite size of samples. The former studies are based upon theoretical hypotheses, mathematical approximations and have not been fully checked experimentally : these formulations are not really usable quantitatively. Starting from potential measurements on circular samples, we present a model for edge effects giving a quantitative formulation, along the contacts axis, that fits well the experimental results. Then, we calculate the edge effect influence on bulk resistance.
\end{abstract}

\section{Introduction.}

When studying any two terminal device or sample, everybody is more or less concerned with the bulk resistance. In fact, this resistance depends on the geometry and not only, in planar technology for example, on the distance between the two electrical contacts. If contacts are far from the edges of sample (let's say an infinite dimension sample), the formulation is quite well known and the only remaining factor is the thickness of the semiconductor $[1,2]$ when resistivity is uniform. For finite size sample, peoples consider pure mathematical geometry cases [1], or nearer to experiment cases like circular or square devices $[3,4]$. However, these studies are based upon theoretical hypotheses, mathematical approximations, and have not been

(*) Visitingscholar at Laboratoire de Physique de la Matière, from Nanjing Aeronautical Institute, Peoples Republic of China.

$(* *)$ This work is related to a C.N.R.S. contract (ATP $\left.n^{\circ} 2216\right)$. checked experimentally. These formulations are not really usable quantitatively for experimental cases. For example, Laplume [3] concludes that for circular samples, edge effects due to finite size are negligible while our experiments prove it is not. Starting from potential measurements on circular samples, we present an experimental-analog model that gives the quantitative formulation for edge effects. This paper deals first with the description of the samples and then with the technique used to get rid of ohmic contacts influence. Starting from the theoretical (infinite) formulation, we find the necessary modifications for taking into account the edge effects and show how they modify the bulk resistance.

\section{Experimental procedure.}

Samples are 2 inch diameter silicon wafers ( $p$ type) with two ohmic contacts, as shown in figure 1 . Ohmic contacts are $2 \mathrm{~mm}$ diameter evaporated aluminium disks annealed at $400^{\circ} \mathrm{C}$ for half an hour. Their characteristics are presented in table $\mathrm{I}$. 


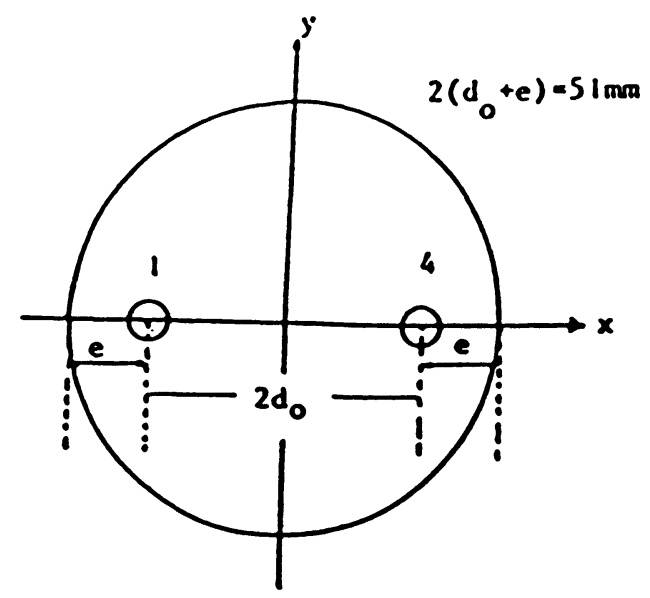

Fig. 1. - Geometry of samples. Silicon wafer with 2 ohmic contacts (1 and 4$)$.

Table I.

\begin{tabular}{|c|c|c|c|c|c|c|}
\hline No & $\begin{array}{c}2 d_{0} \\
(\mathrm{~mm})\end{array}$ & $\begin{array}{c}e \\
(\mathrm{~mm})\end{array}$ & $d_{0} / e$ & $e / d_{0}$ & $\begin{array}{c}\rho \\
(\Omega . \mathrm{cm})\end{array}$ & $\begin{array}{c}C \\
\left(\mathrm{~V}^{-1}\right)\end{array}$ \\
\hline 1 & 23 & 14 & 0.8214 & 1.217 & 19.7 & 95.2 \\
2 & 30 & 10.5 & 1.429 & 0.6998 & 19.4 & 97.2 \\
3 & 37 & 7 & 2.643 & 0.3784 & 17.9 & 105.3 \\
4 & 42.5 & 4.25 & 5.000 & 0.2000 & 17.9 & 105.3 \\
\hline
\end{tabular}

in which :

$$
\begin{array}{ll}
d_{0} \text { and } e & : \text { as defined in figure } 1 \\
f & : \text { thickness of the wafers }(0.3 \mathrm{~mm} \text { for all } \\
& \text { cases }) \\
I & \begin{array}{l}
\text { current injected }(0.2 \mathrm{~mA} \text { for all the } \\
\text { samples })
\end{array} \\
\rho & : \begin{array}{l}
\text { semiconductor resistivity } \\
C=4 \pi f / \rho I:
\end{array} \\
& \begin{array}{l}
\text { constant independent on geometry, } \\
\text { intervening as well for infinite size or } \\
\text { finite size wafers. }
\end{array}
\end{array}
$$

Electrical contacts are made of gold wires stuck by the means of silver paint. A tungsten carbide needle is used to measure potentials everywhere on the sample.

The measurement network is shown in figure 2 . We first set the $1 \mathrm{k} \Omega$ potentiometer in series with $180 \mathrm{k} \Omega$ resistors in order to get $V_{\mathrm{P} 1}=V_{\mathrm{P}} / 2$ (accuracy better than $1 \%)$. Then the tungsten carbide needle is put right in the middle of the sample $(x=0, y=0)$ and we tune the $1 \mathrm{k} \Omega$ variable resistor until the high input impedance $(>100 \mathrm{M} \Omega$ ) millivoltmeter measuring $V$ gives zero reading. We get in such a way the real electrical zero because, with or without edge effects, the geometry is so that the voltage at $x=0$ is just half the total voltage drop across terminals 1 and 4 if ohmic contacts are perfect (zero resistance). Consequently, the equilibrium of the bridge means that the difference between

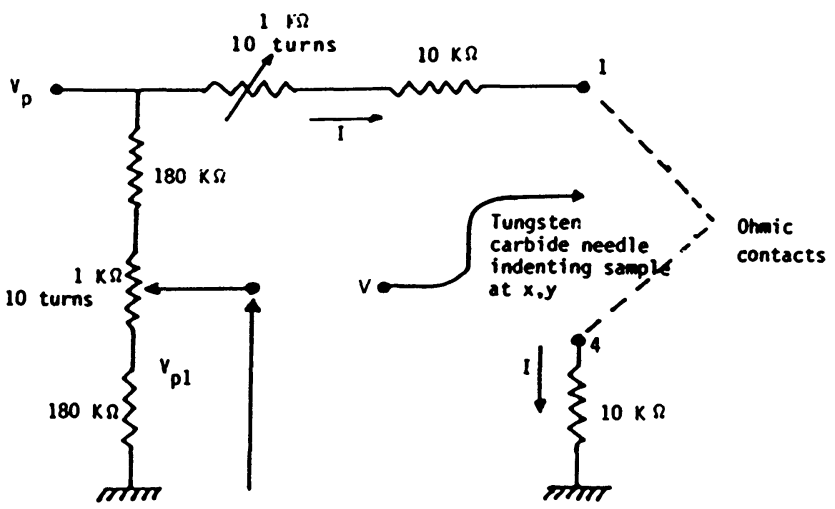

Fig. 2. - Measurement technique. Ohmic contacts 1 and 4 are compensated by high impedance Wheatstone bridge.

the two ohmic contacts is zero, and that the ohmic contact resistances won't intervene anymore in measurements. The $10 \mathrm{k} \Omega$ series resistors whose value is much greater than ohmic contacts ones insure a very low error if the ohmic contacts vary.

3. Comparison of results with theoretical no edge effect case along $x$ axis. For an infinite size sample, that is $e=\infty$ in figure 1 , the formulation for potential $V_{t}$ is [2] :

$$
V_{\mathrm{t}}=\frac{1}{C} \ln \left(\frac{\left(d_{0}+x\right)^{2}+y^{2}}{\left(d_{0}-x\right)^{2}+y^{2}}\right)
$$

The finite dimension of the sample means that current streamlines will be forced into the bulk. The main compression is along the $x$ axis and, to compare results to theoretical case, we first of all calculated what should be $d$, the new value of $d_{0}$, so that equation (1) fits experimental results. Results are shown in figure 3 for samples 1 and 4 . We can conclude that, the higher is $x$, the lower is the difference between $d_{0}$ and $d$. So, for high values of $x$, the compression effect due to edge effects is less and goes down to zero when $x=d_{0}$.

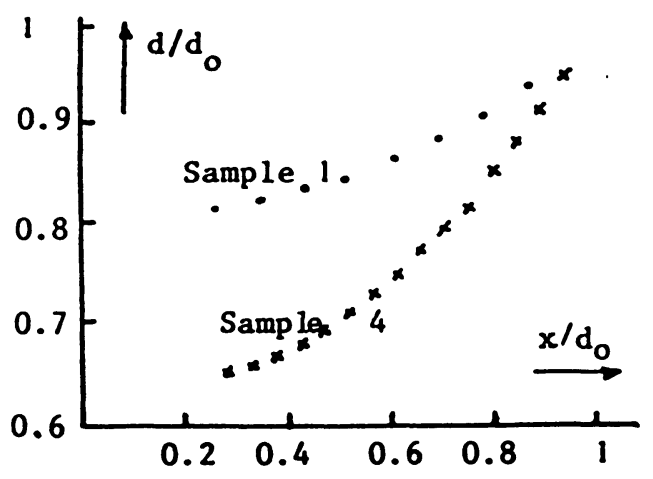

Fig. 3. - Two examples of the comparison of $d$ calculated to fit experimental data (with edge effect) with $d_{0}$ along the $x$ axis. 


\section{Quantitative formulation of edge effects.}

From equation (1), the field $F_{\mathrm{tx} 0}$ (along the $x$ axis) is :

$$
F_{\mathrm{tx} 0}=\left(\frac{\partial V_{\mathrm{t}}}{\partial x}\right)_{(x, 0)}=\frac{4 d_{0}}{C\left(d_{0}^{2}-x^{2}\right)}
$$

and its variation versus $d_{0}$ is :

$$
\frac{\partial F_{\mathrm{tx} 0}}{\partial d_{0}}=-\frac{F_{\mathrm{tx} 0}}{d_{0}} \frac{\left(x^{2}+d_{0}^{2}\right)}{\left(d_{0}^{2}-x^{2}\right)}
$$

The finite size sample is comparable to the infinite one whose electric field has been modified everywhere so that we get the equivalent of all the streamlines pushed inside the sample in order to have the total current inside this finite area. So, the main effect of edge limitations is to increase the current density, and consequently the electric field, for any $x$ position. This is shown by experimental $d$ (cf. Fig. 3) which is lower than $d_{0}$ and $\mathrm{d} F_{\mathrm{tx0}} / \mathrm{d} d_{0}<0$. The absolute value of $\mathrm{d} F_{\mathrm{tx} 0} / \mathrm{d} d_{0}$ increases versus the field and the change of the theoretical field and consequently of $d_{0}$ due to edge effects will be lower when the field is higher. We shall consider, in a first approach, that $d$ depends on $1 / F_{\mathrm{tx} 0}$. Since $1 / F_{\mathrm{tx} 0}$ is proportional to $d_{0}^{2}-x^{2}$, we have fitted $d$, as a function of $x^{2}$ with a polynomial and comparing to well known series, it turned out that the law was exponential. Figure 4 shows this exponential variation for the four samples.

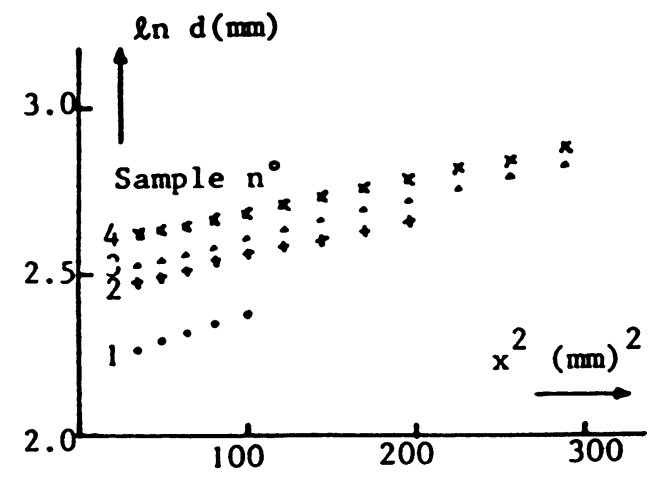

Fig. 4. - The variation of $d$ is an exponential whose exponent is inversely proportional to the electric field calculated without any edge effect (for which $d=d_{0}$ ).

However, the compression of current streamlines is relative to the local electric field as compared to the less strong one, that is to :

$$
F_{\mathrm{t} 00}=\left(\frac{\partial V_{\mathrm{t}}}{\partial x}\right)_{(0,0)}=\frac{4}{C d_{0}} .
$$

But from figure 3 , we know that $d$ tends to $d_{0}$ when $x=d_{0}$, that is for $F_{\mathrm{tx} 0}$ reaching « infinite value ». From these two last remarks, and considering figure 4 and equations (2) and (3), we get :

$$
\begin{aligned}
& d=d_{0} \exp \left(-B \cdot F_{\mathrm{t} 00} / F_{\mathrm{tx} 0}\right) \\
& d=d_{0} \mathrm{e}^{-B} \cdot \exp \left(B x^{2} / d_{0}^{2}\right)
\end{aligned}
$$

in which $B$ depends only on geometrical factors responsible for edge effects.

The coefficient $B$ must be zero when there is no edge effect $(e=\infty)$ because in that case we must have $d=d_{0}$ whatever $x$. This term $B$ has no unit and it is logical to think it will depend on a ratio of two parameters associated with the edge effect. This ratio could be $e / d_{0}$ or $d_{0} / e$. Since, physically, we must have a finite solution when $e=0$, we choose $e / d_{0}$ as the parameter. From these last comments, one can suppose that $B$ is proportional to an exponential of $e / d_{0}$ of course with a negative exponent. We show in figure 5

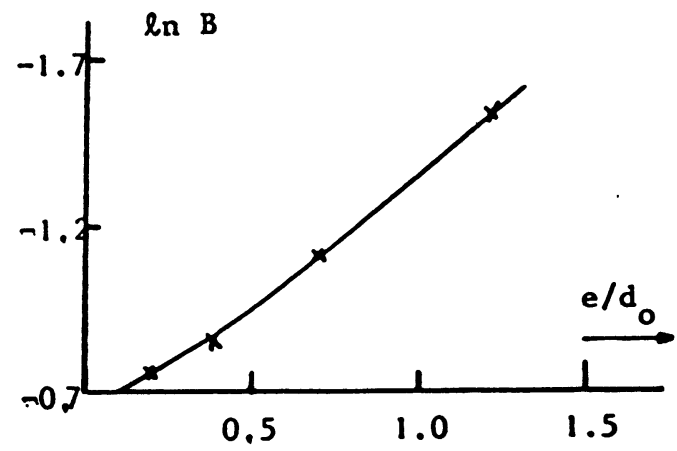

Fig. 5. - First attempt to find a formulation relating the dependence on the electric field to the edge effect characteristic parameter $e / d_{0}$.

the plot of $\ln B$ versus $e / d_{0}$. This curve has been fitted, by the means of the least square method, to a parabola. We get :

$$
\ln B=-0.622\left(1+0.922 e / d_{0}+0.204 e^{2} / d_{0}^{2}\right) .
$$

The term in the parentheses looks very much like $\left(1+e / 2 d_{0}\right)^{2}$. We have plotted, in figure $6, \ln B$ versus this new edge effect parameter. This fit is very good and the linear regression gives finally:

$$
\ln B=-0.070-0.556\left(1+e / 2 d_{0}\right)^{2}
$$

with a correlation factor equal to 0.9985 . So, we have :

$$
B=0.932 \exp \left(-0.556\left(1+e / 2 d_{0}\right)^{2}\right) .
$$

This last relation gives then the solution for the edge effect along the $x$ axis. The procedure is the following :

- calculate $B$ from equation (8) 


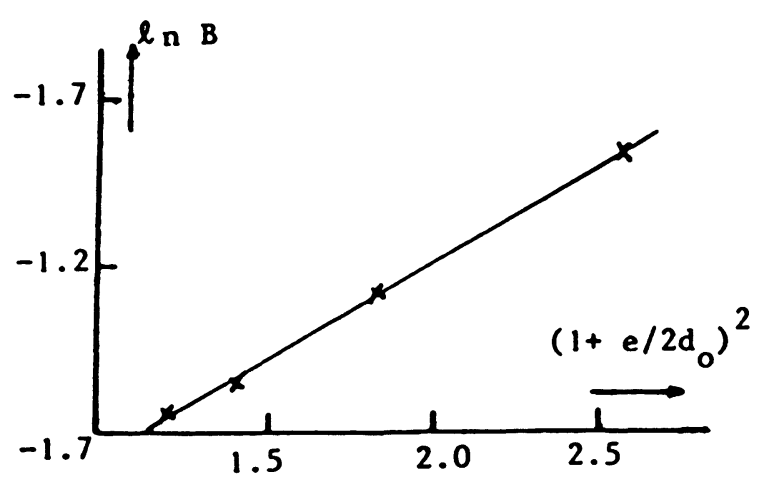

Fig. 6. - Representation of the final formulation used to relate the electric field to the edge effect characteristic parameter $e / d_{0}$.

- put this value of $B$ in equation (5) to get $d$

- then the use of equation (1), replacing $d_{0}$ by $d$ gives the potential with edge effect $\left(V_{\mathrm{e}}\right)$.

We have compared the experimental data to the calculations issued from our model. This one agrees pretty well with the experiment. The differences along the $x$ axis are less than $2 \%$, for all the samples when $x / d_{0}$ is greater than 0.4 . In fact, this covers a great part of sample surface and is satisfactory for conditions involved when calculating the bulk resistance for the two contact geometry.

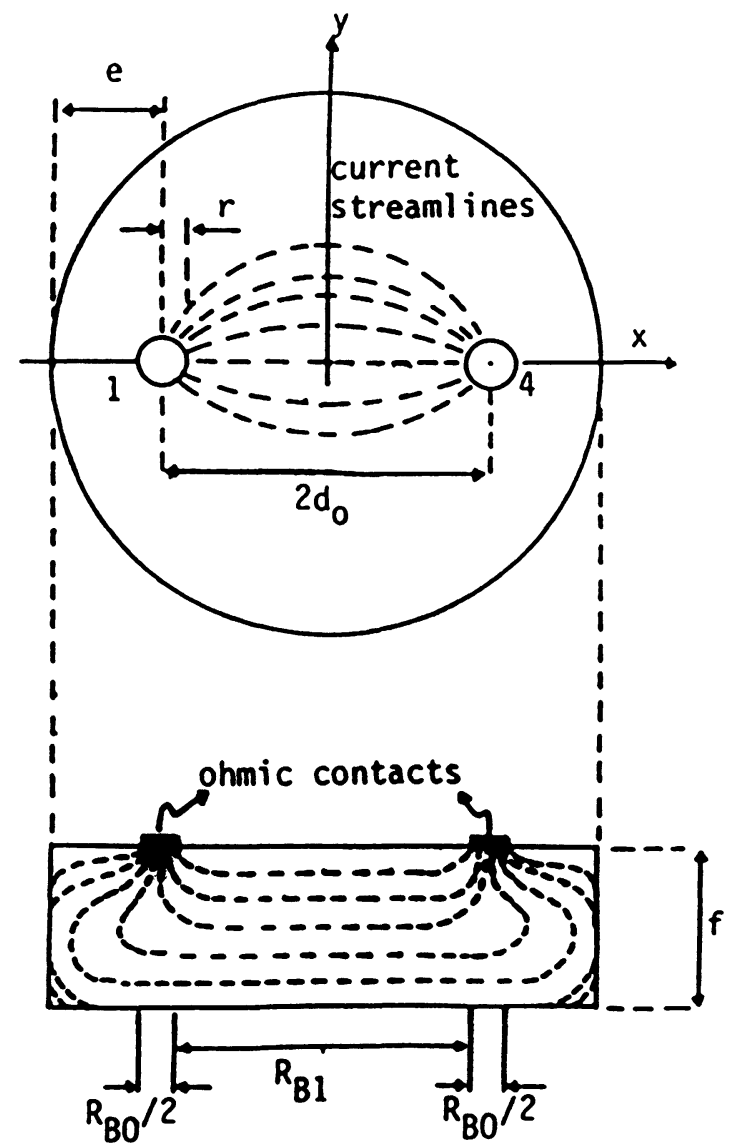

Fig. 7. - Representation of current stramline paths intervening in bulk resistance calculation.

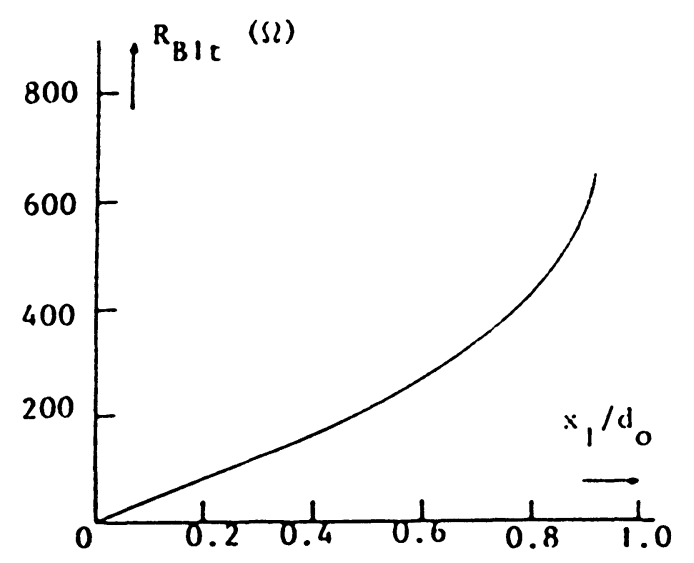

Fig. 8. - Resistance of the bulk, without any edge effects, for the region located from $-x_{1}$ to $x_{1}$.

\section{Bulk resistance with edge effects.}

When we consider the two ohmic contact geometry of figure 1 , the current streamlines distribution is qualitatively the one shown in figure 7 . So, the equivalent

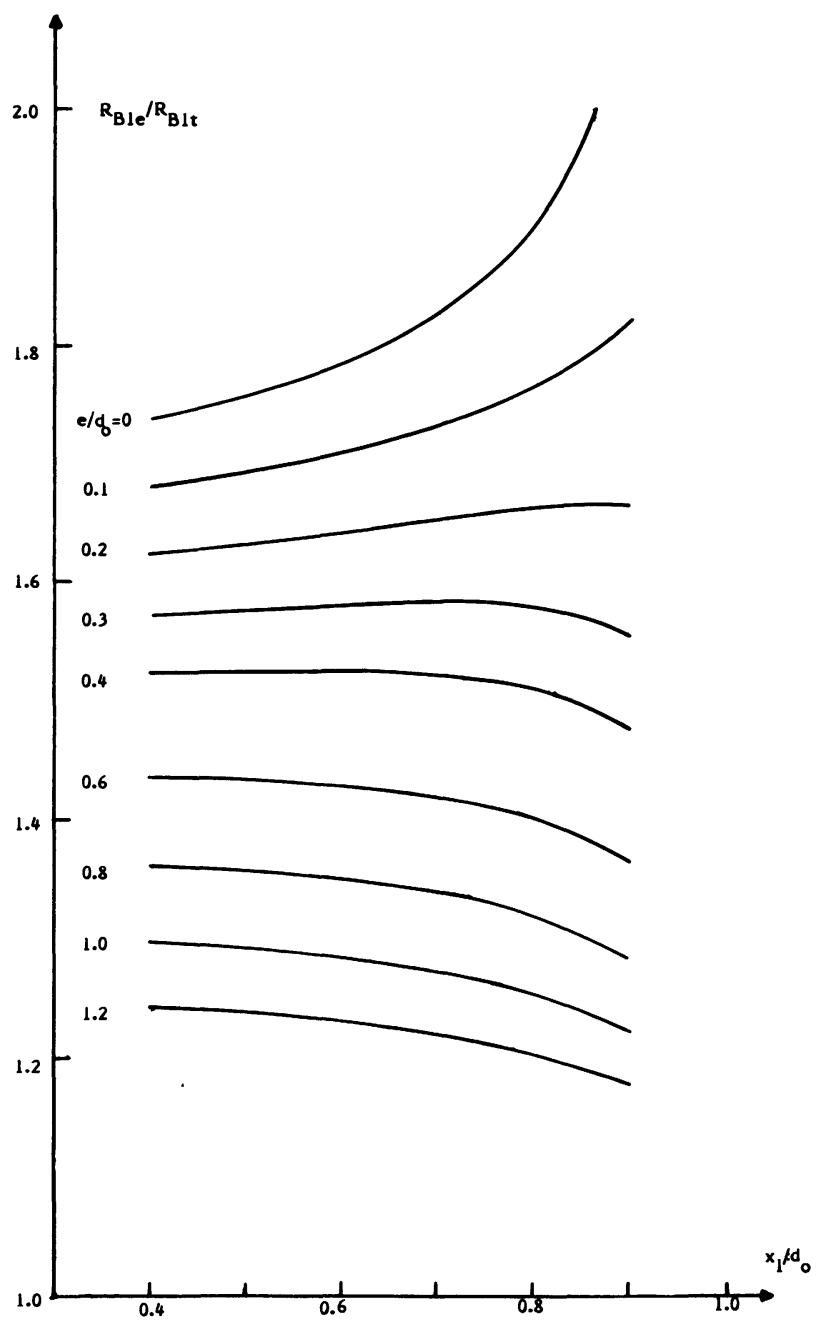

Fig. 9. - Bulk resistance with edge effects as compared to the one without any edge effects. 
total resistance between the electric contacts can be fairly determined by :

$$
R_{\mathrm{t}}=R_{\mathrm{C} 01}+R_{\mathrm{C} 04}+R_{\mathrm{B} 0}+R_{\mathrm{B} 1}
$$

in which :

$R_{\mathrm{C} 01}$ and $R_{\mathrm{C} 04} \quad$ : resistance of ohmic contacts 1 and 4

$R_{\mathrm{B} 0} \quad:$ resistance due to the curvature of current streamlines in the bulk part located under ohmic contacts

$R_{\mathrm{B} 1} \quad$ : resistance only due to current streamline paths in the bulk outside ohmic contacts.

In order to show the influence of edge effects on the bulk resistance, we calculate $R_{\mathrm{B} 1}$ without any edge effect $\left(R_{\mathrm{B} 1 \mathrm{t}}\right)$ and with edge effect $\left(R_{\mathrm{B} 1 \mathrm{e}}\right)$. For the bulk extending from $-x_{1}$ to $x_{1}$, we get from equation (1) :

$$
R_{\mathrm{B} 1 \mathrm{t}}=\frac{2 V_{\mathrm{t}}\left(x_{1}\right)}{I}=\frac{2}{I C} \ln \left[\frac{d_{0}+x_{1}}{d_{0}-x_{1}}\right]^{2}
$$

and

$$
R_{\mathrm{B} 1 \mathrm{e}}=\frac{2 V_{\mathrm{e}}\left(x_{1}\right)}{I}=\frac{2}{I C} \ln \left(\frac{d+x_{1}}{d-x_{1}}\right)^{2} .
$$

Figure 8 shows the dependence of $R_{\mathrm{B} 1 \mathrm{t}}$ on $x_{1}$, that is in fact on the size of the ohmic contact as compared to $d_{0}$. On another hand, we have plotted in figure 9 $R_{\mathrm{B} 1 \mathrm{e}} / R_{\mathrm{B} 1 \mathrm{t}}$ which gives directly the influence of edge effect. The latter increases the bulk resistance. Qualitatively, edge effects will increase the current density under the ohmic contact and lower $R_{\mathrm{B} 0}$.

\section{Conclusion.}

The aim of our study was to find from potential measurements, a quantitative model for edge effects. In this paper, we present an analog-experimental solution for the $x$ axis (axis of the two ohmic contacts) that agrees very well with experimental data.

We have used our formulation to calculate the equivalent bulk resistance in the two contact geometry. The effect of edges is then to increase this resistance and this could be of some importance when studying barriers like grain boundaries. Our quantitative model is then the very specific tool to be used.

We think that, physically, the 0.932 constant in equation (8) ought to be 1 . We intend to extend our model in order to have the solution over all the sample. Then the many more data involved should probably enable us to get an even more precise formulation for equation (8). Finally, our formulation combined with Valdes [1] calculations for thickness influence gives the solution for different thickness circular samples.

\section{References}

[1] VAldes, L. B., Resistivity measurements on Germanium for transistors, Proc. I.R.E., p. 420-427, 1954.

[2] Legros, R., Les semiconducteurs. Tome 1 (Ed. Eyrolles), 1974.

[3] Laplume, J., Bases théoriques de la mesure de la résistivité et de la constante de Hall par la méthode des pointes. L'Onde Electrique. XXXV, n ${ }^{\circ} 335$ (1955) 113-125.

[4] Wieder, H., Electrical and galvanometric measurements on thin films and epilayers, Thin Solid Films, 31 (1976) 123-138. 